\title{
THE ESTIMATION OF THE TEMPERATURE OF COPPER BY MEANS OF OPTICAL PYROMETERS.
}

\author{
. $\quad$ By G. K. Burgess.
}

The experiments here described are a part of a proposed series of determinations of such thermal properties of materials, at high temperatures, as are of considerable technical interest.

The measurement of the temperature of inaccessible masses of hot metal, whether liquid or solid, is of prime importance to the metallurgist, and it is generally recognized that an optical or radiation pyrometer, sighted upon a clear surface of liquid metal, such as iron or copper, indicates too low a temperature if the pyrometer has been calibrated in the usual way in terms of the radiation from an inclosure approximating a black body. ${ }^{1}$ It was in order to furnish the data needed for an approximately correct estimate of the temperature of liquid and solid copper by means of optical pyrometers using monochromatic light and by means of pyrometers using total radiation that the following experiments were undertaken. Some preliminary observations have also been made on iron, but further work has been postponed until the greater facilities of the new heat laboratory now in course of erection are available. It is also hoped to make similar measurements on aluminum, brass, bronzes, and special steels.

It is a very difficult matter to determine accurately by any method the true temperature of the surface of a mass of metal, although in the case of metals which are good conductors and at the same time poor radiators, as is liquid copper, the uncertainties are reduced to a minimum. As what is generally desired,

\footnotetext{
${ }^{1}$ See "Optical Pyrometry," C. W. Waidner and G. K. Burgess, this Bulletin 1, p. I89, 1905, and "Pyrometer Testing and Heat Measurements," Cir. Bureau of Standards, No. 7 .
} 
however, is not the temperature of the surface of the metal, but of its mass as a whole, this difficulty is of minor importance, since the corrections to the optical pyrometer sighted on the surface may be given so as to reduce its readings to the temperature at some definite region within the mass of the metal. A complete experimental study of the temperature distribution within a considerable bulk of cooling copper has not as yet been undertaken, but a preliminary attempt is here made to determine, to a degree of accuracy sufficient for most technical needs, the relation between the readings of the two types of radiation pyrometers above mentioned and those of a thermocouple whose junction is placed just beneath the surface of the metal.

Arrangement of Experiments. - The experiments were carried out in a darkened room during September and October, I 908, using an American Gas Furnace Company's No. 3 melting furnace for melting the copper, which was contained in shallow crucibles, both magnesia and graphite, of $8-\mathrm{cm}$ inside diameter. With the cover of the furnace removed, the gas and air supply could be so regulated that either a clear copper surface or one of oxide could be obtained at will on the liquid copper, the crucible being so set in the furnace that the flames did not play directly on the metal surface in line with the optical pyrometer.

The crucible was set so high in the furnace that radiation from the inside walls of the furnace could not be reflected into the pyrometer, which was pointed at the copper surface at an angle of $25^{\circ}$ to $30^{\circ}$ with the vertical. In the case of the rough oxide surface diffuse reflection from the furnace walls may affect the optical readings, especially if the walls are hotter than the oxide surface. This effect was shown to be small, in the experiments where monochromatic light was used, by changing the height of the crucible in the furnace; but it becomes serious when using the whole spectrum. When sighting on the pure copper liquid surface, which forms a mirror, there is only specular reflection from bright objects to contend with, and in this case the metal may be at the bottom of a deep furnace, and no error can arise from reflection from furnace walls or other incandescent sources unless they can actually be seen in the pyrometer telescope. 
In order to measure the true temperature of the layer of copper immediately beneath the surface, a thermocouple was inclosed in a thin porcelain tube bent into the form of a crook, in the tip of which was placed the junction of the couple. This method of introducing the thermocouple had the advantage of leaving virtually the whole surface of the copper open to the view of the optical pyrometer, besides eliminating any error in the temperature readings arising from conduction along the thermocouple wires.

The Pyrometers.-The temperature readings of the platinum, platinum-rhodium thermocouple were taken with a Siemens and Halske pyrometer galvanometer of 400 ohms resistance. The optical pyrometer used was of the Holborn and Kurlbaum type, using the Morse principle of disappearing lamp filament, although the results obtained apply equally well for any type of optical instrument using the same red-colored light, such as the Wanner and Féry-absorption pyrometers and the Morse thermogage when the last is provided with a suitable red glass between the lamp and eye, as in the Holborn-Kurlbaum type of this instrument. There will still be a small correction, however, for the slightly differing reds used in these various instruments. In order to bring out the effects of selective emission in the radiation from copper, measurements were also taken with green glasses in place of the red between the eye and the pyrometer lamp. The total radiation instrument used was a Féry reflecting telescope, with gold mirror. It is probable that other total-radiation pyrometers would give results differing slightly from those found here, and even two Féry instruments would probably not give identical results.

All the instruments used were calibrated in terms of the standard temperature scale, on which the melting points of pure zinc, antimony, and copper are taken as $419^{\circ} .0,630^{\circ} .5$, and $1084^{\circ} \mathrm{C}$, respectively. The temperature of the copper freezing point is lowered by the presence of cuprous oxide, and in a gas furnace, unless a reducing atmosphere is maintained, the copper usually begins to freeze out on cooling at temperatures between $1075^{\circ}$ and $1080^{\circ} \mathrm{C}$. That the thermocouple whose junction was just beneath the surface of the copper was really indicating a tem- 
perature not far from the true temperature of this free surface of metal was evidenced by the fact that, as the crust began to form, the thermocouple never read higher than $1080^{\circ}$, and usually within $5^{\circ}$ of $1075^{\circ} \mathrm{C}$.

\section{MEASUREMENTS WITH THE OPTICAL PYROMETER.}

On Clear Liquid Copper.-To a sufficient degree of accuracy for all practical purposes the relation between the apparent temperature of the clear surface of the metal free from oxide, as given by an optical pyrometer using monochromatic light, and the actual temperature of this surface is linear.

For liquid copper possessing a mirror surface free from oxide and haze we find the following equations to hold for red and green light, respectively:

(I) Red light $(\lambda=0.65 \mu): t=\mathrm{I} .5 \mathrm{I} 5 r-359$

(2) Green light $\left(\lambda=0.55^{\mu}\right): t=\mathrm{I} .5 \mathrm{I} 5 g-477$

where $t$ is the true temperature centigrade of the copper and $r$ and $g$ the apparent temperatures given by the optical pyrometer using red and green light, respectively. It will be seen that at the melting point of copper the pyrometer using red light reads $130^{\circ} \mathrm{C}$ too low, and that the apparent temperatures with green light are higher than those with red light by a constant amount over the whole temperature range, namely, by $78^{\circ} \mathrm{C}$.

The precision attained in these measurements is shown in Table I, in which the computed temperatures satisfy equations (I) or (2).

In deducing equations (I) and (2) a slight allowance was made for the fact that the optical readings would tend to be high, due to the slightest impurity on the copper surface.

On Cuprous Oxide.-When the copper freezes, or when an oxide coating forms on the liquid, the readings of the optical pyrometer will be higher than when sighted on the pure metal. For a thin coating of oxide floating on the liquid the optical pyrometer using red light reads approximately $100^{\circ} \mathrm{C}$ higher than when sighted on the clear metal. When green light is used, 
the change from metal to oxide increases the apparent temperature by only about $35^{\circ} \mathrm{C}$, indicating the relatively greater intensity of the green in the light emitted by liquid copper. This greenish appearance persists in incandescent solid copper, as may be seen by adjusting the gas feed to remove the surface oxidization.

TABLE I.

Temperatures of Molten Copper with Optical Pyrometers.

\begin{tabular}{|c|c|c|c|c|c|}
\hline \multicolumn{3}{|c|}{ With red glass: $\lambda=0.65 \mu$} & \multicolumn{3}{|c|}{ With green glass: $\lambda=0.55 \mu$} \\
\hline \multicolumn{2}{|c|}{ Temperature Centigrade } & \multirow{2}{*}{ Comp.-obs. } & \multicolumn{2}{|c|}{ Temperature Centigrade } & \multirow{2}{*}{ Comp.-obs. } \\
\hline Computed & Observed & & Computed & Observed & \\
\hline $1073^{\circ}$ & $1077^{\circ}$ & $-4^{\circ}$ & $1082^{\circ}$ & $1087^{\circ}$ & $-5^{\circ}$ \\
\hline 1075 & 1075 & 0 & 1083 & 1087 & -4 \\
\hline 1075 & 1075 & 0 & 1092 & 1101 & -9 \\
\hline 1075 & 1081 & -6 & 1107 & 1104 & +3 \\
\hline 1077 & 1075 & +2 & 1115 & 1119 & +4 \\
\hline 1085 & 1085 & 0 & 1154 & 1153 & +1 \\
\hline 1085 & 1081 & +4 & 1154 & 1141 & +13 \\
\hline 1085 & 1096 & -11 & 1159 & 1172 & -13 \\
\hline 1090 & 1079 & +11 & 1159 & 1159 & 0 \\
\hline 1090 & 1093 & -3 & 1182 & 1188 & -6 \\
\hline 1090 & 1096 & -6 & 1187 & 1195 & -8 \\
\hline 1094 & 1096 & -2 & \multicolumn{2}{|c|}{ a. d. of a single obs.. } & $6^{\circ} \mathrm{C}$ \\
\hline 1094 & 1098 & -4 & & & \\
\hline 1114 & 1118 & -4 & & & \\
\hline 1123 & 1117 & +4 & & & \\
\hline 1129 & 1129 & 0 & & & \\
\hline 1133 & 1131 & +2 & & & \\
\hline 1145 & 1145 & 0 & & & \\
\hline 1147 & 1148 & -1 & & & \\
\hline 1157 & 1155 & +2 & & & \\
\hline 1159 & 1160 & -1 & & & \\
\hline 1185 & 1185 & 0 & & & \\
\hline 1208 & 1212 & -4 & & & \\
\hline \multicolumn{2}{|c|}{ a. d. of a single obs.......... } & $3^{\circ} \mathrm{C}$ & & & \\
\hline
\end{tabular}


Corrections to Optical Pyrometer Readings.-Table II and Fig. I give approximately the true temperatures in terms of the readings of optical pyrometers using red light when sighted upon either the clear copper or the oxide. It will be noticed that for the oxide the relation between the optical readings and the true temperatures is not quite linear. If the liquid surface is hazy, encircled by flames, or only partly oxidized, the optical readings will lie somewhere between the two curves $B$ and $D$.

TABLE II.

Temperatures with Optical Pyrometer.

[Red Light: $\lambda=0.65 \mu$.]

\begin{tabular}{c|c|c|c}
\hline \multicolumn{2}{c|}{ Liquid Copper } & \multicolumn{2}{|c}{ Cuprous Oxide } \\
\cline { 2 - 3 } Pyrometer Reading & $\begin{array}{c}\text { Temperature } \\
\text { Centigrade }\end{array}$ & Pyrometer Reading & Temperature Centigrade \\
\hline $950^{\circ}$ & $1082^{\circ}$ & $900^{\circ}$ & $903^{\circ}$ \\
975 & 1118 & 950 & 958 \\
1000 & 1156 & 1000 & 1020 \\
1025 & 1193 & 1050 & 1087 \\
1050 & 1231 & 1100 & 1159 \\
& & 1150 & 1233 \\
\hline
\end{tabular}

MEASUREMENTS WITH TOTAL RADIATION PYROMETER.

The measurements of surface temperature by this method are much less satisfactory than with the optical pyrometer, as slight changes in the properties of the surface produce a much more marked effect on the readings of an instrument using the whole spectrum, visible and invisible, than of one using only a narrow spectral band.

With the Féry pyrometer used in these experiments, the difference in reading at the melting point of copper, when sighted, first on the clear copper and then on the oxide, was from $275^{\circ}$ to $300^{\circ}$ $\mathrm{C}$, and the apparent temperature of freezing as given by the Féry instrument sighted on the clear liquid was slightly less than $600^{\circ}$ $\mathrm{C}$, instead of $1075^{\circ}$ or $1080^{\circ} \mathrm{C}$, as given by the thermocouple, so 
that according to the condition of the copper surface, the corrections to the readings of this instrument lie between $480^{\circ}$ and $175^{\circ}$ $\mathrm{C}$ at the copper melting point. Even a very slight haze or fog over the copper surface will cause a rise of $25^{\circ}$ or $50^{\circ}$ in the F'éry reading, and the presence of flames will change the readings by amounts uncertain both in quantity and direction. The depth of the crucible in the furnace and the effects of radiation from the furnace walls also influence the readings considerably, unless the copper surface is absolutely clear.

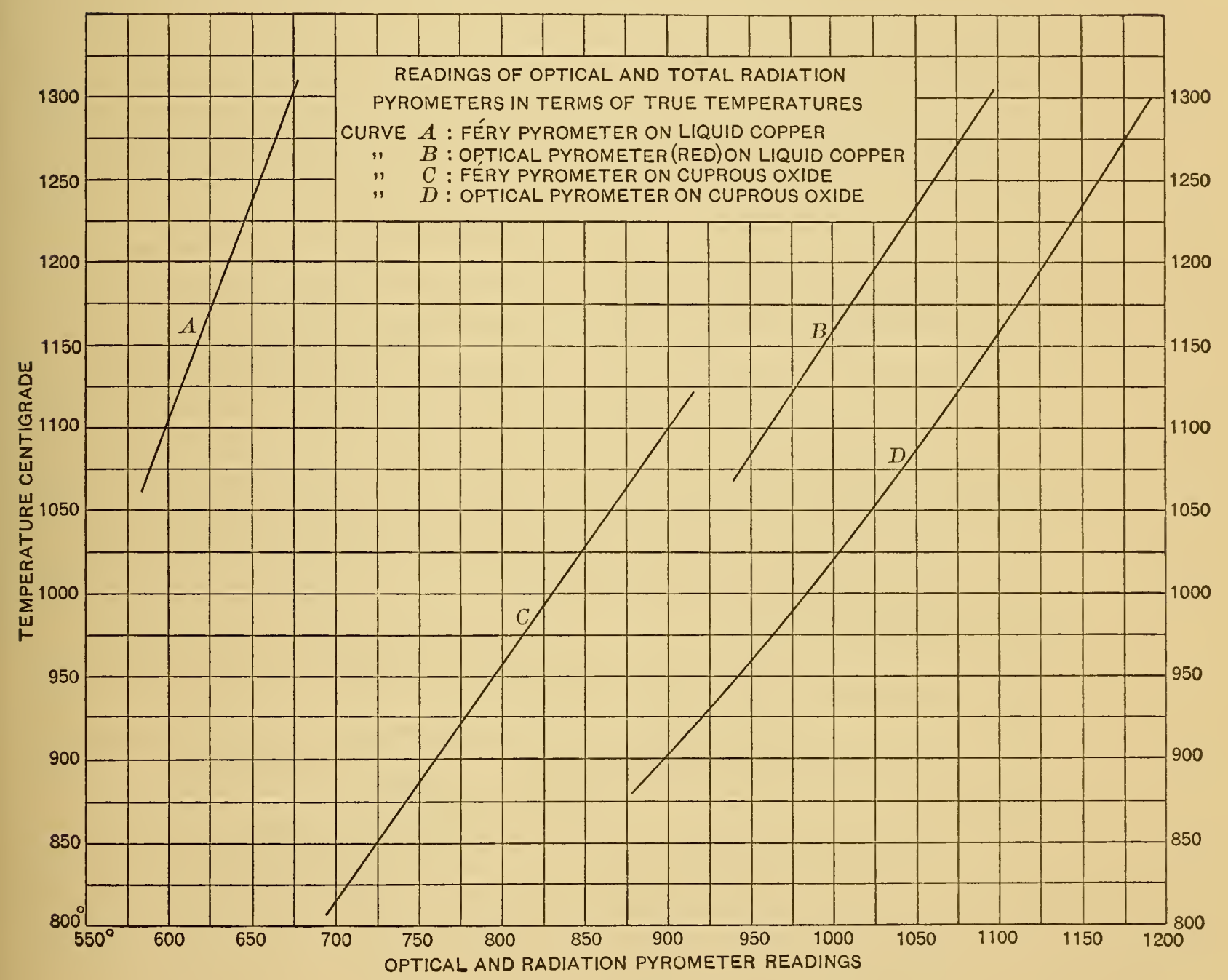

Fig. 1.

The readings of the Féry pyrometer, in terms of true temperature, both for the clear copper surface and for the oxide surface, are given in Fig. I, lines $A$ and $C$. 
These observations satisfy the following equations:

Liquid copper: $t=3.55 F-$ Ior 8

Cuprous oxide: $t=\mathrm{I} .4 \mathrm{r} F-\mathrm{x} 69$

where $t$ is the true temperature centigrade and $F$ the reading of the Féry pyrometer.

\section{EMISSIVITY OF COPPER AND CUPROUS OXIDE.}

The results obtained from the temperature measurements on liquid copper and cuprous oxide may be expressed in terms of their emissivities; that is, by the ratio of the intensity of radiation, either monochromatic or total, for each of these substances to the corresponding intensity of radiation of a black body taken as unity.

\section{TABLE III.}

Emissivity of Liquid Copper and of Cuprous Oxide.

\begin{tabular}{|c|c|c|c|c|c|c|c|}
\hline \multicolumn{4}{|c|}{ Liquid Copper } & \multicolumn{4}{|c|}{ Cuprous Oxide } \\
\hline \multirow{2}{*}{$\begin{array}{l}\text { Temperature } \\
\text { Centigrade }\end{array}$} & \multicolumn{2}{|c|}{$e_{x}$ for -} & \multirow{2}{*}{$E_{x}$} & \multirow{2}{*}{$\begin{array}{l}\text { Temperature } \\
\text { Centigrade }\end{array}$} & \multicolumn{2}{|c|}{$e_{x}$ for- } & \multirow{2}{*}{$E_{x}$} \\
\hline & $\lambda=0.65 \mu$ & $\lambda=0.55 \mu$ & & & $\lambda=0.65 \mu$ & $\lambda=0.55 \mu$ & \\
\hline $1075^{\circ}$ & 0.17 & 0.47 & 0.16 & $800^{\circ}$ & & & 0.66 \\
\hline 1125 & .15 & .38 & .15 & 900 & ..... & & .60 \\
\hline 1175 & .14 & .32 & .15 & 1000 & 0.80 & & .56 \\
\hline 1225 & .13 & .28 & .14 & 1100 & .60 & 0.68 & .54 \\
\hline 1275 & & & .13 & 1200 & $(.49)$ & $(.49)$ & \\
\hline
\end{tabular}

For monochromatic light we have, for the emissivity, $e_{x}$, of a substance:

$$
\log e_{x}=\frac{\mathrm{I} 4500}{\lambda} \log \epsilon\left(\frac{\mathrm{I}}{T_{x}}-\frac{\mathrm{I}}{T_{b}}\right)
$$

where the subscript $x$ refers to the substance under investigation and $b$ to the black body, $\lambda$ is the wave length of the light used, $T$ is absolute temperature, and $\epsilon$ the Naperian base of logarithms. 
For total radiation the emissivity, $E_{x}$, is given by:

$$
\log E_{x}=4\left(\log T_{x}-\log T_{b}\right)
$$

These quantities are given in Table III for both copper and cuprous oxide.

Thwing ${ }^{2}$ also finds $E_{x}=0 . \mathrm{I}_{4}$ for molten copper with his total radiation pyrometer sighted on a stream of the metal.

These experiments were carried out with the able assistance of Mr. J. J. Crowe.

WAShington, June i 7 , I909.

${ }^{2}$ C. B. Thwing: On the Emissivity of Molten Iron and Copper, Phys. Rev. 26, p. I90; 1908 . 